\title{
Sojourner Cultural Adaptation Toward National Culture Change
}

\author{
Nazirah Abdul Rohman, Rozeyta Omar
}

\begin{abstract}
National cultue is affecting sojourner's daily routines in their host countries. Much of the focus surrounding national culture change has targeted the environment. A few systematic reviews have been carried out on the social impacts of national culture change among sojourners in a host country. The present article set out to analyze the impact of cultural adaptation's practices toward national culture change. This review was used PRISMA Statement (Preferred Reporting Item for Systematic Review and Meta-Analysis) method and database search using Web of Sciences and Scopus. Based on this review, a total number of 45 articles were identified related to sojourners cultural adaptation towards national culture change. The review from previous studies suggest that sojourners had an experience faced cultural adaptation's phase likes honeymoon phase, culture shock phase, adjustment phase and adaptation phase in order to adapt with host national culture.
\end{abstract}

Keywords : Sojourner, Cultural Adaptation, National Culture Change

\section{INTRODUCTION}

In recent years, due to economic development and globalization processes, a numbers of sojourners travelling from their original countries to other countries were increased [1]. It was seen that not only do they contribute to the development of host national country, but they also present a diversity of cultures in that country. Moua [2] has indicated that different cultures are strongest over the mainland centers of Western, such as United States, United Kingdom, Australia, Brazil, and Finland. However, most sojourners from China, Republic of Korea, Japan, Taiwan, United Arab Emirates, Indonesia, and Malaysia have been found to face the difficulties of cultural adaptation in their host country [3]. National culture change has been proven to affect cultural norms, beliefs, traditions, languages, and customs [4]. Alghamdi and Otte [1] have indicated that national culture change may also influence the work values and patterns, cultural values, leadership styles, communication styles, and cultures within an organization.

As the impact of national culture change on the environment worsens, cultural adaptation is thus seen as the best remedy [5]. According to Kuo [6], cultural adaptation can be defined as a process of adjusting one's self to be consistent with an unfamiliar culture or environment. It also involves cultural adaptation phase's such as honeymoon

Revised Manuscript Received on October15, 2019

* Correspondence Author

Nazirah Abdul Rohman*, Azman Hashim International Business SchoolUniversity of Technology Malaysia, Johor, Malaysia.. Email: nazirah.abdulrohman@yahoo.com

Rozeyta Omar, 2School of Human Resource Development and Psychology, University of Technology Malaysia, Johor, Malaysia. Email: rozeyta@utm.my phase, culture shock phase, adjustment phase and adaptation phase in order to ensure easy adaptation to the new culture [7], [8]. In the scope of this review, the terms of national culture change, cultural clashes, and cultural differences were used interchangeably. National culture refers to a set of norms, behaviors, beliefs, customs, values, and traditions shared by individuals within their respective communities [9]. Cultural clash can be defined as cultural conflict or otherwise be comprehended as the conflict that occurs due to the interaction between different cultural values [10]. Cultural differences can be understood as the differences in practices and values from one's original culture. This will lead to cultural conflict and culture shock [11].

A. A systematic review of the framework on sojourners' cultural adaptation practices towards national culture change

A systematic review is an examination of clearly formulated questions that uses systematic and explicit methods to identify, select, and critically appraise relevant research, and then collect and analyze the data from past research works that are included in the review. Statistical methods may not be used to analyze and conclude in this review. From this review, research on the impact sojourner cultural adaptation on national culture change, concerted efforts to systematically review these research works are still lacking. This article attempts to fill the gap in understanding, identifying, and categorizing the national culture change adaptation patterns among sojourners. Reports on cultural adaptation in the peer-reviewed literature are used as a proxy of cultural adaptation, underscoring that this research provides a general and baseline overview of cultural adaptation in other countries. The work fills an important gap in the literature due to most systematic reviews having examined cultural adaptation efforts in international students, buyer-seller, expatriates, and immigrants [12].

This research attempts to analyze the existing literature on sojourner cultural adaptation practices towards national cultural change. This section explains the purpose of conducting a systematic review, while the second section details the methodology and PRISMA Statement approach used. Then, the third section systematically reviews and synthesizes the scientific literature to identify, select, and analyze relevant research topics on sojourner cultural adaptation towards national culture change. The last section in this research identifies future research directions. 


\section{Sojourner Cultural Adaptation Toward National Culture Change}

\section{METHODOLOGY}

PRISMA was used to shape the systematic review, which detailed the eligibility and exclusion criteria, the steps of the review (identification, screening, eligibility) and data abstraction and data analysis [13]. The database searching in this review were used Web of Sciences and Scopus.

\section{A. PRISMA}

According to Moher et al. [13], PRISMA offers three unique advantages, which are: (1) identifying a clear research question that permits systematic research, 2) defining the inclusion and exclusion criteria, and 3) examining a large database of scientific literature within a defined time period. This methodology may or may not be used in the end for monitoring the sojourner cultural adaptation practices towards national culture change in the host country.

\section{B. RESOURCES}

This review utilized two main journal databases, which were Web of Science and Scopus. Web of Science is a robust database consisting of $>65,000$ journals and offers coverage for more than 141 disciplines, including subjects related to cross-cultural management, social sciences, anthropology, sociology, and social issues. It includes more than hundreds of years of comprehensive back file and citation data, which has been established by Clarivate Analytics and ranked by separate measures, such as citations, papers, and citations per paper.

The second database used in this review was Scopus. It is one of the largest abstract and citation databases of peer-reviewed literature, with $>20,900$ journals from 150 subject areas worldwide. Scopus consists of diverse subject areas, such as cross-cultural management, sociology, social sciences, business, management and accounting, anthropology, psychology, multidisciplinary and cultural adaptation.

\section{ELIGIBILITY AND EXCLUSION CRITERIA}

The eligibility and exclusion criteria were determined by the reviewer. First, with regard to the literature type, only journal articles with empirical data were selected in this review. Therefore, review articles, book series, books, chapters in books, documentation, statistic reports, and conference proceedings were excluded. Second, in order to avoid any confusion and difficulty in translating, the search efforts excluded non-English publications. Third, a period of 10 years was selected, specifically between the years 2009 and 2019, which was deemed an adequate amount to see the evolution of research and related publications. As the review process focused on cultural adaptation practices towards national culture change, articles in social sciences-based indexes were selected. Therefore, articles published in hard science index (i.e. Science Citation Indexed Expanded) were excluded. Finally, in line with its objective focus on sojourners in the host country, only articles detailing on sojourners and different countries were selected in this review (Figure 1).

\section{DATA ABSTRACTION AND ANALYSIS}

The remaining 45 articles were assessed and analyzed in this systematic review. Efforts were concentrated on specific studies that responded to the formulated objectives and research questions. The data were extracted by reading through the abstract, and then the full articles (in-depth) in order to identify the appropriate themes and sub-themes. Qualitative analysis was performed using content analysis to identify the themes related to cultural adaptation among sojourners towards a national culture change in the host country.

\section{FINDINGS}

From this review, a number of 45 articles were identified related to sojourner's cultural adaptation in host national culture. A total of 19 studies focused on cultural adaptation in United States, while six studies focused on China, nine studies focused on Australia, five studies focused on Norway, Western Europe, Russia, and Japan, respectively, and one study focused on Brazil, Africa, Spain, India, Malaysia, and Taiwan, respectively.

With regards to publication year, ten articles were published in 2018, followed by five articles in 2017, six articles in 2016, seven articles in 2015, two articles in 2014, three articles in 2013, four articles in 2012, two articles in 2011, three articles in 2010, and three articles in 2009.

\section{A. Cultural adaptation among sojourners towards national culture change}

This section concentrated on the main cultural adaptations practiced by sojourners in host countries, namely the honeymoon phase, culture shock phase, adjustment phase and adaptation phase.

\section{- Honeymoon phase}

A total of 12 out of 37 studies focused on the honeymoon phase to cope with national culture change impacts. Ren, Yunlu, Shaffer, and Fodchuk [15] found that migrants changed their attitudes as a way to cope with national culture change impacts. The honeymoon phase is one of the adaptation measures undertaken by Western sojourners as their culture may react differently to the articles culture impacts [16]. For example, Western sojourners expressed difficulties in adapting to different culture context in Taiwan [17]. By practicing cross-cultural adaptability is thus seen as one of the solutions as it enables one to adapt to new culture and environment. Mazrouei and Pech [18] also found that Western sojourners faced difficulty to adapt to different national cultures in Arabic countries. It is because national culture context includes cultural norms, beliefs, values, languages, food and lifestyle were different in other countries [19]. The different national culture context may influenced on cultural adaptation among sojourners [16]. Past studies indicated that if sojourners did not take any solution in early premature stage in host country, it's may effect on psychological and sociocultural adaptation [6], [9], [11].

\section{- Culture shock phase}

Culture shock phase is often found in studies on sojourners cultural adaptation. A total of 18 articles reported that sojourners faced the cultural shock phase during adapting to national culture change. Several studies indicated that personalities and attitudes were influenced by the cultural adaptation process of the expatriate [20], [21].

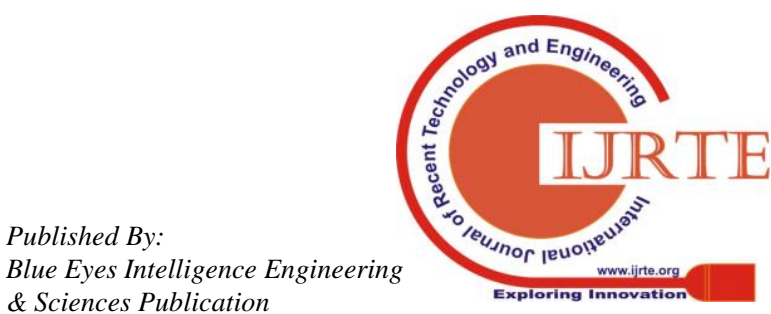


For example, past studies in Japan indicated that national culture in terms of language, norms, food, beliefs, traditions, and attire was different compared to Western regions. Sojourners practiced cultural coping strategies such as problem-focused coping and emotion-focused coping in order to adapt easily with different national culture in Japan [22]. Coping strategies may help sojourners to manage environment's problem and instability emotion effectively [23]. The study from Lim, Bogossian, and Ahern [24] indicated that by using coping strategies during environment stress likes culture shock able to manage and minimize psychological stress such as depression, homesickness, marginalization and isolation.

\section{- Adjustment phase}

A total of 14 studies reported on the adjustment phase practices of sojourners in relation to national culture change adaptation. Due to the impact of national culture change such as cultural norms, beliefs, religion, lifestyle, food, attire, traditions, and music, the overall elements of culture adaptation are affected. Sojourners are forced to adapt to the new national culture to avoid repatriation [29]. Other than that, the adjustment phase can also reduce culture conflict such as cultural clashes in the host country [30]. Sojourners can also try to increase their awareness, knowledge, and experience by getting involved in community activities. In Japan and Russia, for example, sojourners are found to react to national culture change by practicing coping strategies in order to easily adapt to the new culture. The coping strategies function as by gaining positive reappraisal, planned problem-solving, and having self-control to sojourners in host country.

\section{- Adaptation phase}

A total of 16 studies reported the adaptation phase as one of the cultural adaptation measures practiced by sojourners. The adaptation phase can be practiced when the sojourners are facing cultural conflicts in adapting to national culture differences [25]. Research in Indonesia identified that Western sojourners practice the problem focused coping strategies as it easily adapts to national culture change [26], [27]. Gom, Jiony, Tanakinjal, and Siganul [28] indicated that to reduce cultural conflicts in a multicultural country, Western sojourners should have openness and flexible personality characteristics. Other than that, previous international experience, social support and knowledge about host country may help sojourners adapt effectively in national culture change [27]. Studies in Malaysia indicated that sojourners did not have problem to adapt in language because the English languages recognizes as a second language in the country [28]. However, sojourners may difficult to adapt with cultural norms, values, lifestyles and beliefs in Malaysia due to Malaysia having multicultural ethic [28].

\section{DISCUSSION AND FUTURE DIRECTION}

This study attempted to systematically analyze the previous literature on sojourners cultural adaptation practices towards national culture change. A rigorous review sourced from two databases (i.e. Web of Sciences and Scopus) resulted in 45 articles related to sojourner cultural adaptation practices. The results indicated that sojourners engaged in diverse practices. Within the scope of this review, four cultural adaptation phases were identified, namely the honeymoon, culture shock, adaptation, and adjustment phases.

Future researchers should consider using more qualitative designs as they offer in-depth analysis and detailed explanation of sojourner cultural adaptation practices. Gupta and Bhaskar [31] have noted that explicit and detailed reporting of analysis methods for qualitative reviews can result in improved transparency and increased the ability to critically assess the rigor of review methods while reflecting new and diverse systematic methods concomitantly for research synthesis.

\section{CONCLUSION}

From this systematic review, sojourners from different cultural background may face cultural adaptation stages likes honeymoon phase, culture shock phase, adjustment phase and adaptation phase in order to adapt with host national culture. Sojourners also need to practiced coping strategies such as problem focused coping or emotion focused coping during cultural adaptation. From this review, future researcher should focus on another variables such as personality, cultural intelligent, social support and previous international experience in order to sojourners adapt effectively in different national culture.

\section{REFERENCES}

1. H. Alghamdi and S. Otte, "The Challenges and Benefits of Study Abroad,” Int. J. Humanit. Soc. Sci., vol. 6, no. 5, pp. 16-22, 2016.

2. M. Moua, "Culturally Intelligent Leadership: Leading Through Intercultural Interactions," 2010.

3. S. Narayanan, "The Determinants Of Self Initiated Academic Expatriates' Performance In Malaysia," 2014.

4. K. Bierwiaczonek and S. Waldzus, Socio-Cultural Factors as Antecedents of Cross-Cultural Adaptation in Expatriates, International Students, and Migrants: A Review, vol. 47, no. 6. 2016.

5. X. Chen, X. Liu, W. Yu, A. Tan, C. Fu, and Z. Mao, "Association between cross-cultural social adaptation and overseas life satisfaction among chinese medical aid team members (CMATMs) in Africa," Int. J. Environ. Res. Public Health, vol. 16, no. 9, pp. 1-11, 2019.

6. B. C. H. Kuo, "Coping, acculturation, and psychological adaptation among migrants: a theoretical and empirical review and synthesis of the literature," Heal. Psychol. Behav. Med., vol. 2, no. 1, pp. 16-33, 2014

7. S. Lysgaard, "Adjustment in a foreign society: Norwegian fulbright grantees visiting the United State," Int. Soc. Sci. Bull., 1955.

8. J. S. Black and M. Mendenhall, "The U-Curve Adjustment Hypothesis Revisited: A Review and Theoretical Framework," J. Int. Bus. Stud., 1991.

9. M. Minkov and G. Hofstede, "Is National Culture a Meaningful Concept? Cultural Values Delineate Homogeneous National Clusters of In-Country Regions," Cross-Cultural Res., 2012.

10. Uz, "Do cultures clash?," Soc. Sci. Inf., vol. 54, no. 1, pp. 78-90, 2015

11. D. Livermore and L. Van Dyne, "Cultural Intelligence: The Essential Intelligence for the 21st Century Sponsored by," SHRM Found. Eff. Pract. Guidel. Ser. Cult., 2015.

12. M. A. Bhatti, M. M. Battour, A. R. Ismail, and V. P. Sundram, "Effects of personality traits (big five) on expatriates adjustment and job performance," Equal. Divers. Incl., vol. 33, no. 1, pp. 73-96, 2014

13. D. Moher et al., "Preferred reporting items for systematic review and meta-analysis protocols (PRISMA-P) 2015 statement," Rev. Esp. Nutr. Humana y Diet., 2016.

14. S. Lysgaard, "Adjustment in a foreign society: Norwegian Fulbright grantees visiting the United States.," Int. Soc. Sci. Bull., 1955.

15. H. Ren, D. G. Yunlu, M. Shaffer, and K. M. Fodchuk, "Expatriate success and thriving: The influence of job deprivation and emotional stability," J. World Bus., vol. 50, no. 1, 2015.

16. M. Frese, "Perceived organizational support and intention to stay in host countries among self-initiated expatriates: the role of career satisfaction and networks," Int. J. Hum. Resour. Manag., vol. 25, no. 14, pp 2013-2032, 2014 


\section{Sojourner Cultural Adaptation Toward National Culture Change}

17. H. L. Cheng and C. Y. Y. Lin, "Do as the large enterprises do? Expatriate selection and overseas performance in emerging markets: The case of Taiwan SMEs," Int. Bus. Rev., vol. 18, no. 1, pp. 60-75, 2009.

18. H. Al Mazrouei and R. J. Pech, "The expatriate as company leader in the UAE: cultural adaptation,” J. Bus. Strategy, vol. 36, no. 1, pp. 33-40, 2015.

19. W. Macpherson, "How the Japanese Interpret Kaizen: An Exploration of Japanese Spirit," 2013.

20. S. S. Ramalu, R. C. Ros, J. Uli, and N. Kumar, "Personality and Cross-Cultural Adjustment among Expatriate Assignees in Malaysia," Int. Bus. Res., vol. 3, no. 4, pp. 96-104, 2010.

21. Peltokorpi and F. J. Froese, "The impact of expatriate personality traits on cross-cultural adjustment: A study with expatriates in Japan,” Int. Bus. Rev., vol. 21, no. 4, pp. 734-746, 2012.

22. G. M. Breakwell, Coping with threatened identities. 2015.

23. E. M. Chai, R. and Rogers, "Cross-cultural adaptation of U.S. expatriates in Singapore," Media Asia, 2004.

24. J. Lim, F. Bogossian, and K. Ahern, "Stress and coping in Singaporean nurses: A literature review," Nursing and Health Sciences. 2010.

25. S. Sri Ramalu, R. Che Rose, J. Uli, and N. Kumar, "Cultural intelligence and expatriate performance in global assignment: The mediating role of adjustment," Int. J. Bus. Soc., vol. 13, no. 1, pp. 19-32, 2012.

26. F. J. Froese and V. Peltokorpi, "Cultural distance and expatriate job satisfaction,” Int. J. Intercult. Relations, vol. 35, no. 1, pp. 49-60, 2011.

27. Y. L. Chen, M. C. Liu, T. W. Tsai, and Y. H. Chen, "Religious practices in cross-cultural contexts: Indonesian male science students' adjustment in Taiwan," J. Couns. Psychol., vol. 62, no. 3, pp. 464-475, 2015.

28. D. Gom, M. M. Jiony, G. H. Tanakinjal, and R. S. Siganul, "Understanding Cultural Differences in Ethnic Employees ' Work Values : A Literature Review," vol. 5, no. 2, pp. 112-118, 2015.

29. J. Lauring and J. Selmer, "The supportive expatriate spouse: An ethnographic study of spouse involvement in expatriate careers," Int. Bus. Rev., vol. 19, no. 1, pp. 59-69, 2010.

30. F. Jia, R. Gao, R. Lamming, and R. Wilding, "Adaptation of supply management towards a hybrid culture: the case of a Japanese automaker," Supply Chain Manag. An Int. J., vol. 21, no. 1, pp. 45-62, 2016.

31. S. Gupta and A. U. Bhaskar, "Doing business in India: cross-cultural issues in managing human resources," Cross Cult. Strateg. Manag., vol. 23, no. 1, pp. 184-204, 2016.

\section{AUTHORS PROFILE}

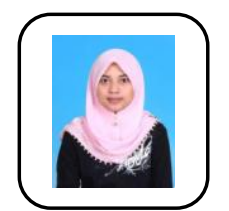

Nazirah Abdul Rohman is presently a $\mathrm{PhD}$ student at Azman Hashim International Business School in the University of Technology Malaysia, Johor, Malaysia. She has completed her Master and Bachelor Degree in Human Resource Development in University of Technology Malaysia, Johor, Malaysia. She actively involved in research and publishing articles in management and cultural studies.

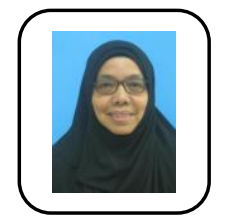

Dr Rozeyta Omar is an Associate Professor in Sociology and Cross Cultural Management at the School of Human Resource Development and Psychology in University of Technology Malaysia, Johor, Malaysia. Her research interest includes sociology and cultural studies. She teaches cultural studies courses and supervises degree, master and doctoral projects within these fields. 